\title{
Self-punitive avoidance behavior in the mouse
}

\author{
PHYLLIS D. BRISTER and KENNETH B. MELVIN \\ University of Alabama, University, Alabama 35486
}

\begin{abstract}
Mice were trained to avoid shock by leaving a startbox and traversing a straight alley. During the first extinction phase (Phase I), two groups were given 30 regular extinction (RE) trials, while another two received punished extinction (PE) trials in the center of the alley. During the last 50 extinction trials (Phase II), conditions were reversed for one of the two groups receiving the same treatment in Phase I. This resulted in two nonshifted groups (RE-RE and PE-PE) and two shifted groups (RE-PE and PE-RE). $\mathrm{PE}$ treatment led to higher running speed in both phases and reversed an extinction trend. Furthermore, punishment-induced facilitation $w$ as greater for the group receiving $\mathrm{PE}$ following $\mathrm{RE}$ than for the group receiving $\mathrm{PE}$ immediately after avoidance training.
\end{abstract}

Under certain conditions, punishment administered during the extinction of an aversively motivated running response may maintain or even enhance the punished response. As recent reviews of the literature reveal (Brown, 1969; Melvin, 1971), the conditions leading to the development of this self-punitive or vicious-circle behavior (VCB) have been well documented -at least as far as the laboratory rat is concerned. The vicious circle effect has also been demonstrated in gerbils (Byrum \& Melvin, 1972; Martin, Ragland, \& Melvin, 1970). Compared with rats, the gerbils tended to extinguish quickly during regular extinction (RE) conditions, presumably due to their strong competing exploratory responses. Since mice have been found to be superior to gerbils in active avoidance learning (Boice, Boice, \& Dunham, 1968), they might also show stronger and more stable vicious-circle behavior than gerbils.

In addition to the comparative features of this experiment, we examined the progressive increase in running speed over punished extinction (PE) trials-the learning of self-punitive running-noted in a number of investigations (Beecroft \& Bouska, 1967; Melvin \& Martin, 1966; Melvin \& Smith, 1967). Separate speed measures for preshock and shock sections of the alley were employed, allowing an assessment of the differential contributions of the shock punishment and conditioned fear to the "learning effect."

A shift design similar to that used by Melvin and Smith (1967) and Byrum and Melvin (1972) was employed, which enabled us to examine differential trends within subjects as well as between groups. Since previous research using the shift procedure suggests that the asymptotic performance of the shifted groups might be superior to that of their nonshifted counterparts, two nonshifted groups (i.e., typical VCB experimental and control groups) were also included in the design.

This report is based on the first author's $M$. A. thesis, which was carried out under the direction of the second author. $A$ portion of this paper was presented at the Southeastern Psychological Association Convention at New Orleans, 1973. Reprint requests should be sent to Kenneth B. Melvin, Department of Psychology, University of Alabama, University. Alabama 35486 .

\section{METHOD}

\section{Subjects}

The subjects were 20 male and 20 female naive albino mice, ranging in weight from 18 to $43 \mathrm{~g}$ at the start of the experiment. Each subject was handled, caged individually with free access to water, and deprived of food for approximately $12 \mathrm{~h}$ prior to testing.

\section{Apparatus}

The runway apparatus consisted of a $12.70-\mathrm{cm}$ startbox, a $45.72-\mathrm{cm}$ straight alley, and a $27.94-\mathrm{cm}$ goalbox. All components were made of Plexiglas and were $8.25 \mathrm{~cm}$ wide and $12.70 \mathrm{~cm}$ high. The sides of the startbox and alley were covered with white adhesive-backed plastic sheeting; both had clear tops and grid floors. The sides and top of the goalbox were covered in black adhesive-backed plastic sheeting, and it had a Masonite floor. A white guillotine door prevented subjects from leaving the startbox; a black guillotine door at the entrance of the goalbox prevented retracing.

Photocells and associated electromechanical equipment were used to control shock presentation and response time measurements (to the nearest $.01 \mathrm{sec}$ ). Prepunishment time was defined as the time from the raising of the startbox door until interruption of the first photobeam $29.21 \mathrm{~cm}$ from the rear of the startbox. Punishment-plus time was the time elapsing between the interruption of the first photobeam and the interruption of the second photobeam $1.27 \mathrm{~cm}$ into the goalbox. During avoidance training and $\mathrm{PE}$, a $55-\mathrm{V}$ shock was delivered through 10K.

\section{Procedure}

The subjects were randomly assigned to one of four groups balanced for sex. The study was run in 10 replications of four mice each.

Avoidance training. Prior the the experimental session, each subject was handled, placed into the startbox, and allowed to explore for $5 \mathrm{~min}$ in the startbox, alley, and goalbox, respectively.

Following exploration, all subjects recived identical avoidance training. The subject was placed in the startbox facing the goalbox, after which the start- and goalbox doors were raised simultaneously. If the subject entered the goalbox within $3 \mathrm{sec}$ after the raising of the doors, shock was prevented. If the subjects failed to enter the goalbox within the 3-sec interval, the grid floor of the startbox and alley was electrified. After the mouse entered the goalbox, the guillotine doors were lowered and subject was allowed to remain in the goalbox for $30 \mathrm{sec}$. The acquisition criterion was five consecutive avoidances within 30 trials. If the subject failed to meet this criterion, it was discarded and a substitution made; six mice were discarded and replaced 


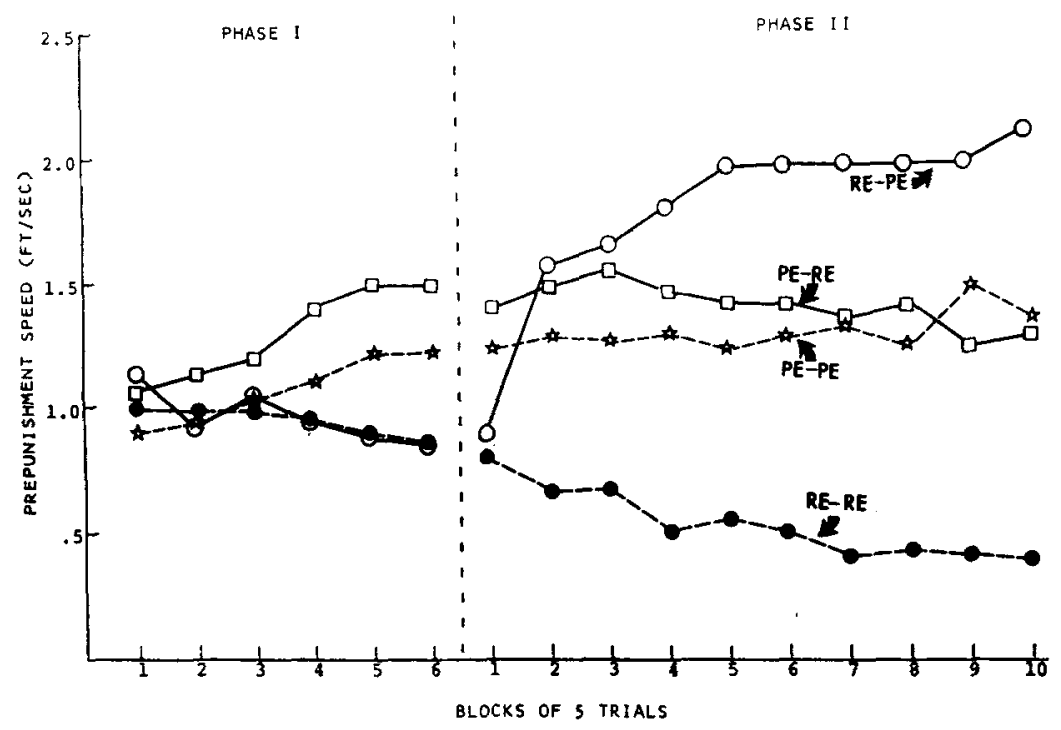

Figure 1. Mean prepunishment speed across blocks of five trials.

on the basis of this criterion.

Extinction. Immediately following avoidance training, all subjects received two extinction phases-the first consisting of the first 30 extinction trials (Phase I) and the second of the next 50 trials (Phase II). Group RE-PE received the RE condition in Phase I and the PE condition in Phase II. Group PE-RE was given $\mathrm{PE}$ in Phase I and RE in Phase II. Groups RE-RE and PE-PE received the same treatment in both phases. During $R E$, no shock was ever present in any part of the apparatus. During PE, shock was present in the middle $15.24 \mathrm{~cm}$ of the alley on each trial. If the subject's total response time exceeded $30 \mathrm{sec}$ in Phase I, it was discarded and a replacement made. This criterion was established to insure the continued responding of subjects until the completion of Phase I in order that the effects of the shift procedure could be assessed. Eight subjects were discarded and replaced on the basis of this criterion. ${ }^{1}$ If the subject's total response time exceeded $60 \mathrm{sec}$ on any trial of Phase II, testing ceased, and scores of $60 \mathrm{sec}$ were recorded. Eight subjects met the extinction criterion.

\section{RESULTS}

A simple analysis of variance of each subject's median prepunishment and punishment-plus speeds over the last five acquisition trials revealed no reliable differences among groups $(\mathrm{p}>.10)$.

\section{Prepunishment Speed}

Each subject's median prepunishment speed scores were obtained for successive five-trial blocks by transforming time scores to $\mathrm{ft} / \mathrm{sec}$. Figure 1 represents the mean prepunishment speeds for the four groups across five-trial blocks. The basic self-punitive effect is evidenced in this figure by the differential performance of Groups RE-RE and PE-PE. This figure shows that, while Group PE-PE maintains its higher speed over blocks of trials, Group RE-RE shows the characteristic extinction trend. Comparison of these two groups revealed statistical significance $(F=11.16, d f=15 / 270$, $\mathrm{p}<.001)$.

Phase I. A 2 by 2 by 6 mixed factorial analysis of variance of the punishment and shift (i.e., shifted vs. nonshifted groups) dimensions across the six blocks of trials constituting Phase I revealed a significant blocks effect and Punishment by Blocks interaction $(F=10.41$, $\mathrm{df}=5 / 180, p<.001)$. The significant interaction reflects the increase in speed shown by the two punished groups and the slight decrease in speed of the nonpunished groups.

Phase II. As Figure 1 suggests, performance during Phase II was strongly influenced by the treatment received in Phase I. This effect was confirmed by the results of a 2 by 2 by 10 analysis of variance of the punishment and shift dimensions across the 10 blocks of trials comprising Phase II. This analysis yielded significant Punishment by Blocks, Shift by Blocks, and Punishment by Shift by Blocks interactions $(F=15.66$; $8.01 ; 2.65$, respectively, $\mathrm{df}=9 / 324$, each $\mathrm{p}<.05$ ). The triple interaction reflects the relatively stable performance, over blocks of trials, of the two groups receiving $P E$ in Phase $I$ and the differential trends in the performance of the groups receiving RE in Phase I. While the running speed of Group RE-PE over the 10 blocks of trials in Phase II shows a dramatic increase, the speed of Group RE-RE continues to decline.

An analysis comparing the running speeds of Groups PE-PE and PE-RE over blocks of trials in Phase II revealed no significant differences.

The deletion or addition of punishment in Phase II provided within-subject comparisons. A $t$ test of the mean decrease in speed from Block 6 of Phase I to Block 10 of Phase II for Group PE-RE proved nonsignificant, whereas a similar test for Group RE-PE revealed a significant difference $(\mathrm{t}=10.33, \mathrm{p}<.001)$. These figures indicate that, while Group RE-PE ran significantly faster with the introduction of punishment in Phase II, here the deletion of punishment for Group PE-RE had no appreciable effect on prepunishment speed. 


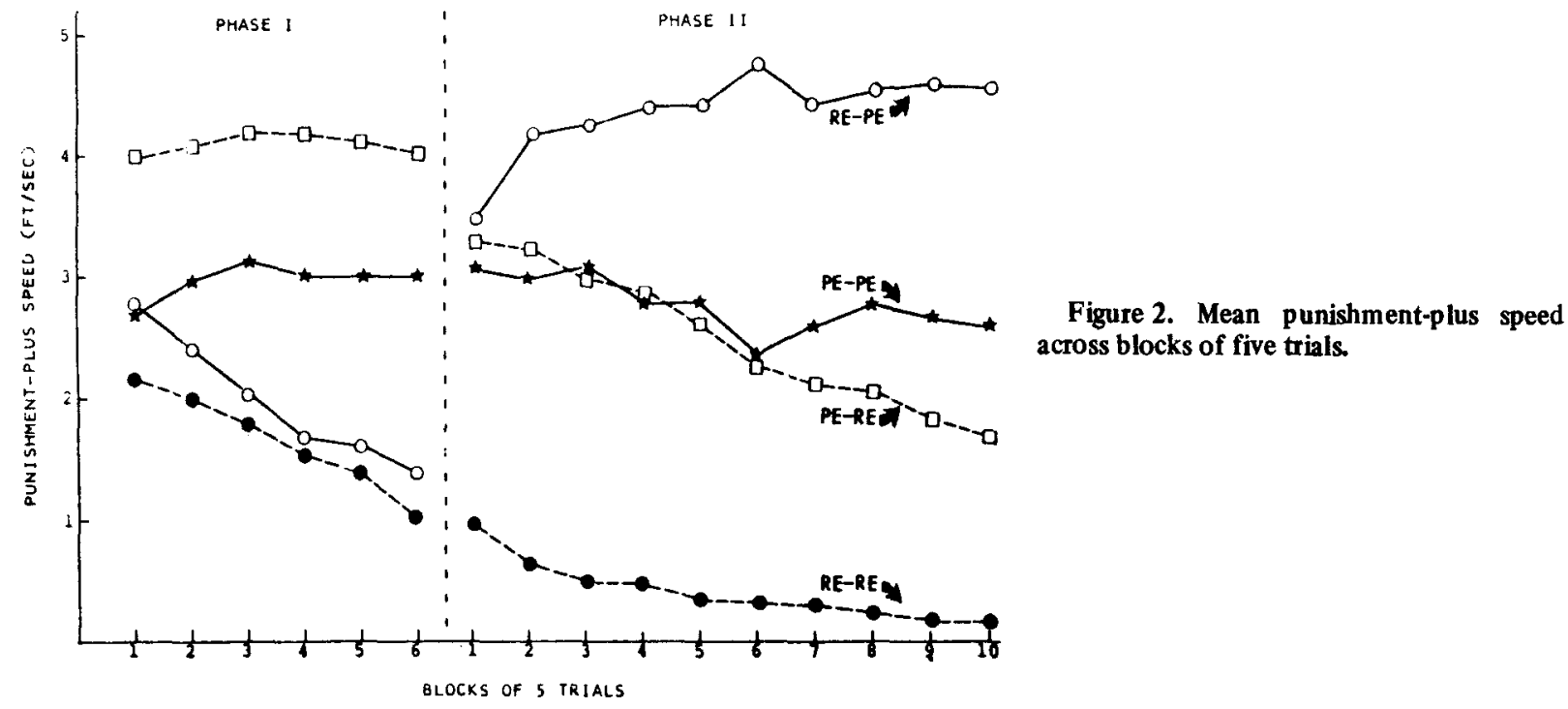

Asymptotic self-punitive running. An analysis comparing speed scores of Group RE-PE over the last three Phase II blocks, with those of Group PE-RE over the last three Phase I blocks yielded only a significant groups effect $(F=10.75, \mathrm{df}=1 / 18, \mathrm{p}<.005)$. These results indicate that $\mathrm{PE}$ following $\mathrm{RE}$ leads to faster running during asymptotic performance than when $\mathrm{PE}$ immediately follows avoidance learning.

A similar comparison of speed scores, over the last six blocks of trials in Phase II, for Groups RE-PE and PE.PE, produced only a significant groups effect $(\mathrm{F}=7.09, \mathrm{df}=1 / 18, \mathrm{p}<.05)$, again demonstrating the superiority of Group RE-PE.

Learning self-punitive running. Figure 1 indicates that prepunishment speed tends to increase over the first 25 trials of PE. A 2 by 16 analysis of variance based on the mean of the last two trials prior to $\mathrm{PE}$ and first 15 two-trial blocks of PE for Groups RE-PE and PE-RE during their respective $P E$ phases yielded significant effects of groups, blocks $(F=17.23, \mathrm{df}=15 / 270$, $\mathrm{p}<.001)$, and their interaction $(\mathrm{F}=4.22, \mathrm{df}=15 / 270$, $\mathrm{p}<.001)$. This interaction reflects the marked increase in speed exhibited by Group RE-PE in contrast to the slight and gradual increase shown by Group PE-RE.

\section{Punishment-Plus Speed}

Figure 2 represents the mean punishment-plus speed ( $\mathrm{ft} / \mathrm{sec}$ ) across five-trial blocks for all four groups. Again the basic self-punitive effect is depicted by the performance of Groups PE-RE and RE-RE; with Group PE-PE maintaining its faster speed across blocks of trials and Group RE-RE exhibiting the characteristic extinction trend. An analysis of speed scores for these two groups over the 16 blocks of trials indicated significant effects of groups, blocks, and their interaction $(F=7.71, \mathrm{df}=15 / 270, \mathrm{p}<.001)$.

Phase I. A 2 by 2 by 6 mixed factorial analysis of variance of the punishment and shift dimensions across the six blocks of trials constituting Phase I resulted in significant main effects of punishment $(F=27.43$, $\mathrm{df}=1 / 36, \quad \mathrm{p}<.001)$, shift $(\mathrm{F}=5.05, \mathrm{df}=1 / 36$, $\mathrm{p}<.05$ ), and blocks as well as a significant Punishment by Blocks interaction $(\mathrm{F}=15.21, \mathrm{df}=5 / 180, \mathrm{p}<.001)$. This interaction reflects the extinction trends exhibited by Groups RE-RE and RE-PE and the relatively level performance, across blocks, shown by Groups PE-PE and PE-RE.

Phase II. As Figure 2 indicates, punishment-plus speed in Phase II was influenced by the treatment received in Phase I, although this effect does not appear to be as strong as that for prepunishment speed. A 2 by 2 by 10 mixed factorial analysis of the punishment and shift dimensions across the 10 blocks of trials in Phase II produced significant main effects, Punishment by Blocks interaction, Shift by Blocks interaction, and Punishment by Shift by Blocks interaction $(F=10.14$, $\mathrm{df}=9 / 324, p<.001)$. The triple interaction reflects the faster running speeds of the two shifted groups relative to their nonshifted counterparts and the differential trends exhibited by the two shifted groups.

Asymptotic self-punitive running. An analysis comparing speed scores of Group RE-PE over the last six Phase II blocks with scores of Group PE-RE over the first six Phase I blocks failed to reveal any significant effects, indicating that, for this particular measure, the effect of shock-punishment on running speed is apparently independent of the phase during which it is introduced.

Despite the fact that Groups RE-PE and PE-PE were not significantly different in training, the significant groups effect $(F=9.78, \mathrm{df}=1 / 18, \mathrm{p}<.01)$ found in the analysis of Phase II speed scores for these groups indicates that Group RE-PE ran significantly faster than Group PE-PE in the shocked section of the alley.

Learning self-punitive running. An analysis identical to those of prepunishment speed, i.e., over 16 two-trial 
blocks. were conducted for punishment-plus speed. The blocks effect and Groups by Blocks interaction $(\mathrm{F}=26.02 .6 .63$, respectively, $\mathrm{d} f=15 / 270, p<.001)$ were significant. This interaction was due to the substantial increase in speed shown by Group RE-PE.

\section{DISCUSSION}

The basic VCB effect was again demonstrated-punishment during the extinction of an avoidance response facilitated the punished response. A within-subjects vicious-circle effect was also obtained, confirming the findings of Byrum and Melvin (1972) with gerbils, and Melvin and Smith (1967) with rats.

Additionally, the results of this investigation serve to extend the generality of the phenomenon by demonstrating the effect in mice, a species not previously used in VCB research. Extrapolation from previous studies (Byrum \& Melvin, 1972; Siegel, Melvin, \& Wagner, 1971), suggests that the self-punitive behavior observed in mice is comparable to that observed in rats and gerbils on both speed measures. However, the rapid extinction trend found in gerbils (Byrum \& Melvin, 1972) was not observed in mice. In fact, no significant decrease in speed was found in the prepunishment area for mice shifted from PE to RE, whereas a significant decrease was reported in the same area for gerbils.

A progressive increase in prepunishment speed was obtained over the first 30 punished trials suggesting that VCB is learned during PE. This "learning effect," clearly evident in the prepunishment section of the alley, was not apparent in the punishment-plus section. Furthermore, although Groups PE-RE and RE-PE exhibited similar incremental trends in prepunishment speed during $P E$, the increase in speed shown by Group RE-PE was much more pronounced. Additionally, Group RE-PE was running faster during asymptotic performance in this section of the alley than Group PE-RE. However, despite this prepunishment speed differential, the speeds of the two groups did not differ significantly in the punishment-plus section. Since differences in prepunishment speed were unaccompanied by differences in the speed with which these two groups traversed the punished section of the alley, the reduction of punishment duration would not appear to play a major role in the observed progressive increase in prepunishment speed. This finding is consistent with results found with rats (Anson, Bender, \& Melvin, 1969).

In demonstrating the learning effect with the prepunishment response measure, the results of the present investigation offer additional support for the Mowrer-Brown condition fear interpretation of VCB (Brown, 1969; Melvin, 1971). However, an explanation of the superior self-punitive performance of
Group RE-PE, relative to Group PE-RE, in the prepunishment section of the alley, requires the incorporation of additional concepts. One explanation would invoke conditioned relaxation (Denny, 1971; Denny \& Dmitruk, 1967). Group RE-PE experiences an interval of extinction (Phase I) between avoidance and $\mathrm{PE}$-thus relaxation would p:ogressively become conditioned to alley cues during this phase. With the introduction of punishment, these RE.PE mice experience more contrast or adaptation-level change than do the mice shifted directly from avoidance to $P E$ (Group PE-RE). Thus, even though the punishment situation is identical for both groups, the total situation is more aversive, i.e., fear arousing, for Group RE-PE, and therefore they run relatively faster.

In summary (a) The basic vicious-circle effect was demonstrated in mice. Shock punishment facilitated running speed in shock and preshock areas, both between and within subjects. (b) An exception to the above was the continued stable performance of PE-RE mice in the prepunishment area even when punishment was eliminated. (c) The group shifted to the punishment condition after receiving extinction trials (RE-PE) ran faster at asymptote than the group (PE-PE) maintained on punishment throughout. During the punishment phase, the former group also exhibited faster asymptotic running in the prepunishment section relative to a group (PE-RE) receiving punishment directly following avoidance training. (d) In general, progressive increments in the speed of self-punitive running occurred over the initial punishment trials, perhaps reflecting the learning of self-punitive running.

\section{REFERENCES}

Anson, J. E., Bender, Lee, and Melvin, K. B. Sources of reinforcement in the establishment of self-punitive behavior. Journal of Comparative and Phy siological Psychology, 1969, $67,376-380$.

Beecroft, R. S., \& Bouska, S. A. Leaming self-punitive running. Psy chonomic Science, 1967, 8, $107-108$.

Boice, R., Boice, C., \& Dunham, A. E. Role of docility in avoidance: Gerbils and Kangaroo rats in a shuttlebox. Psy chonomic Science, 1968, 10,381-382.

Brown, J. S. Factors affecting self-punitive locomotor behavior. In B. A. Campbell and R. M. Church (Eds.), Punishment and aversive behavior. New York: Appleton-Century-Crofts, 1969. Pp. 467-514.

Byrum, R, P., \& Melvin, R. B. Self-punitive avoidance behavior in the Mongolian gerbil. Psychonomic Science, 1972, 28, 13-15.

Denny, M. R. Relaxation theory and experiments. In F. R. Brush (Ed.), A versive conditioning and learning. New York: Academic Press, 1971.

Denny, M. R., \& Dmitruk, V. M. Effect of punishing a single failure to avoid. Joumal of Comparative and Physiological Psychology, 1967, 63, 277-281.

Martin, R. C., Ragland, E., \& Melvin, K. B. Self-punitive locomotor behavior in the Mongolian gerbil. Psychonomic Science, 1970, 20, 183-184.

Melvin, K. B. Vicious circle behavior. In H. D. Kimmel (Ed.), Experimental psy chopathology: Recent research and theory. New York: Academic Press, 1971.

Melvin, K. B., \& Martin, R. C. Facilitative effects of two modes of punishment on resistance to extinction. Journal of Comparative and Physiological Psychology, 1966, 62, 491-494. 
MIelsin, K. B., \& Smith, F. H. Self-punitive avoidance behavior in the rat. Journal of Comparative and Physiological Psychology, $1967,63,533-535$.

Siegel, $\dot{P}$. S., Melvin, K. B., \& Wagner, J. D. Vicious circle behavior in the rat: Measurement problems visited again. Journal of Comparative and Physiological Psychology, 1971, $76,311-315$.

\section{NOTE}

1. Four of these subjects were in the PE condition and four in the RE condition.

(Received for publication June 25, 1974;

revision accepted February 10, 1975.) 